\title{
STUDY OF THE LEARNING CONDITIONS OF THE ELDERLY ACCORDING TO THE PHILOSOPHY
}

\author{
Raweerose Sricompa ${ }^{1}$, Chetthapoom Wannapaisan ${ }^{2}$, Parut Boonsritun ${ }^{3}$ and \\ Somwang Kaewsufong ${ }^{4}$ \\ ${ }^{1,2}$ Faculty of Education, Chiang Mai University, Thailand \\ ${ }^{3,4}$ Faculty of Humanities, Chiang Mai University, Thailand
}

DOI: 10.46609/IJSSER.2021.v06i01.019 URL: https://doi.org/10.46609/IJSSER.2021.v06i01.019

\begin{abstract}
This article is part of a study on the philosophy of living for the elderly for lifelong learning. The purpose of the research is to study the philosophy of living of the elderly for lifelong learning. This is qualitative research by collecting data through the review of relevant documents and research. The tool is an in-depth interview and a specific conversation, conducting studies and selecting examples of elderly people, individuals at the policy level and those associated with the elderly in a specific way based on the importance of the subject is a person who is involved with the elderly in Lampang, Lamphun and Phrae province. In an in-depth interview with 16 people, a total of 48 people were injured, and by group discussion, 10 people in each province, a total of 30 people. The researchers found that in-depth interviews on the philosophy of living of the elderly for lifelong learning, there are five aspects: (1) the philosophy of living in truth, (2) the philosophy of living in knowledge, (3) the philosophy of living in reason, (4) the philosophy of living in virtue of virtue, and (5) the philosophy of living in beauty. The findings bring practical and development approaches to the elderly, as well as individuals and agencies related to the elderly, such as the school of the elderly and the elderly club, as well as the community and society, have used this research to develop activities that will respond to the lives of the elderly for lifelong learning.
\end{abstract}

Keywords: Learning conditions, Elderly, Life Philosophy, Lifelong Learning

\section{Introduction}

The World Assembly on the Elderly in 1982 set the same standard around the world, agreeing that people aged 60 and over are referred to as "elderly". The National Institute on the Elderly, the United States has determined that the elderly aged between 60-74 years are not very old age, but if physical health and mental health are good, at the age of 75 years old, it is truly old age, 


\section{International Journal of Social Science and Economic Research}

ISSN: $2455-8834$

Volume:06, Issue:01 "January 2021"

and the Thai National Statistical Office divides the elderly into the early elderly (aged 60-69 years) and the late elderly (aged 70 years and over). Which, the number of seniors is growing rapidly, in 1993, 7.2\% of the Thai population was aged 60 and over. In 1995, the population increased to $8.11 \%$ and calculated that in 2000, 2010, and 2020, the number of elderly people in Thailand increased to $9.19 \%, 11.36 \%$, and $15.28 \%$ of the total population. By the time people live longer, people in their $60 \mathrm{~s}$ are more likely to live up to the age of 80 , so they may need to look at the elderly, from the picture of an old man can't do anything, waiting for the day of death to the elixir, and quality of life because the age range from 60 years to 80 years for quite a bit more thus helping to maintain health do a lot of useful and enjoyable work. Survey results of The Institute of Population and Social Research, Mahidol University as of July 1, 2019, 8.4\% of the population is elderly. The average life expectancy at birth of males is 66.6 years and females is 71.7 years, while the average life expectancy at age 60 is male to 18.8 years old and females are 22.0 years (Health Promotion Agency, 2019).

Health promotion for the elderly the objective is to provide the elderly with healthy health and health that can take care of themselves. Also, family members and communities are involved in caring for and promoting the health of the elderly, as well as encouraging the elderly to have the opportunity to show their potential to promote their health, family, and community, a multipurpose welfare service unit has been established for the elderly in the community. Also, families and the elderly are involved in the implementation of health care to cover at least $50 \%$ of the elderly population in Thailand. As a result, the average life expectancy of males increased from 68-70 years, and females increased from 72-75 years (Health Promotion Agency, 2019).

Social psychologists say it's difficult to adapt to elderly roles. These things happen because of the work that turns into the elderly, lack of support groups children are taught to learn the role of adolescents, and adolescents are trained to be adults, but only a few adults are trained to be elderly, and modern people see their traditional cultural values as obsolete, bonding between brothers and kinship. However, gratitude must be limited. Therefore, there is a modern culture that is different from self-help, for those who can live in modern society, it must be capable of formulating it's all about knowledge and it's important to be self-sufficient. For this reason, the elderly who will be in Thai society for the next 10-20 years must be elderly with physical, mental, knowledge, and capacity. Overall, it means that the "elderly" must have strong community potential (Ministry of Social Development and Human Security, 2014).

The elderly are individuals with knowledge and experience, who are qualified and qualified, are valuable human resources, even if the elderly enter the day that the weak body is deteriorating, but still ready and able to help the family. For example, helping to take care of your child while parents go out to work, help to look after the house, some elderly people can also do a lot of food and help with a little work based on the force. It also provides advice on areas such as career, 


\section{International Journal of Social Science and Economic Research}

ISSN: $2455-8834$

Volume:06, Issue:01 "January 2021"

lifestyle, and family, social, and so on and some of the elderly have some professional skills. Such as carpentry, carver, Thai cooking, Thai dessert, embroidery, flowers, and music, it will be passed on to children and those who are interested in establishing the profession. (Office of Child Welfare and Welfare, 2014)

The rise of the elderly in the Thai social context Impact on government management economic and social, as well as to individuals, families, and communities (Academic Office, Secretariat, House of Representatives, 2018) As a result, the elderly themselves need to change the way they think and behave in terms of knowledge. The process of change occurs at an aging age and the nature of the elderly in various dimensions so that they can live a normal, happy life, and to make the elderly a valuable person in society for the surrounding persons and entities associated with the elderly. Such as nursing homes and organizations that organize missions related to the elderly. For example, local government organizations and senior schools, etc. Therefore, measures must be taken to properly engage with those elderly. However, with the characteristics of the elderly, they are qualified, knowledgeable, capable, and skilled and experience in a variety of lives. There are names such as community sage, local sage, wisdom teacher, and life experts, etc. It is accepted and is generally seen in Thai society, reflecting the powerful potential of the elderly to the community and society. It shows that the lives of the elderly are related to consumerism, beliefs, customs, traditions, cultures, and religions that are harmoniously blended according to the identity of each local. These are the elderly who have a philosophy of living.

The next one is the principle of lifelong learning that helps the elderly to have a direction to live in a normal society. In this regard, it is vital and essential for the elderly to learn to adapt to their families, the community, and society are in line with the changing environment at all times. Lifelong learning covers key features: systematic, student-centered, motivated to study, and the objectives of a variety of educational policies. Lifelong learning creates a solid foundation for all people, focuses on all forms of learning, resource allocation, and utilization of resources from all sectors, and requires the cooperation of all sectors (Life-long Learning, Policy Brief, Organization for Economic Co-operation and Development, OECD, 2004).

The lifelong learning needs of the elderly should be held up for the health of most seniors in the 60-64 age range. In this regard, the education managers are wisdom teachers or communityeducated. In the form of short-term training, the most preferred media and learning resources are individual, in terms of assessment based on the condition, and require elderly clubs to promote a lifelong education management network. Therefore, the researchers are interested in studying the philosophy of living of the elderly for lifelong learning. The findings are for the elderly, including individuals and agencies related to the elderly. Such as school, seniors, and geriatric sorority, etc. In total, the community and society have used this research to develop activities that are in response to the lives of the elderly for lifelong learning. 
International Journal of Social Science and Economic Research

ISSN: 2455-8834

Volume:06, Issue:01 "January 2021"

\section{Research Objectives}

To study the philosophy of living of the elderly for lifelong learning

III. Conceptual Framework

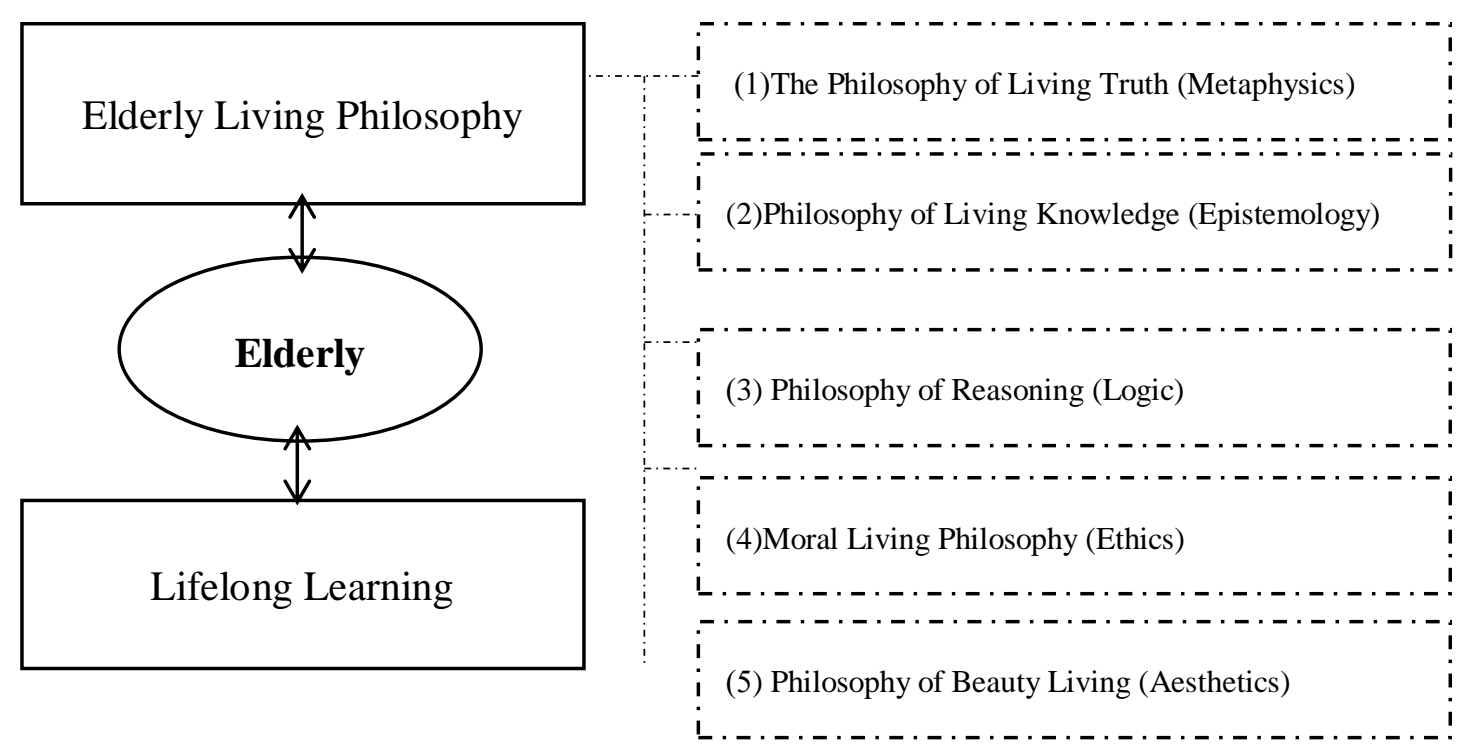

Figure 1: Conceptual framework of the research

\section{Literature Review}

\section{Concept of philosophy}

\subsection{Definition of philosophy}

The Royal Dictionary (2011) gave the meaning "philosophy" meaning the subject of the principle of knowledge and truth. Which PhraDhammakosaj (PrayoonThomchitto) (2012) has given the meaning that "philosophy" is a Sanskrit word that matches the Pali word "wisdom", meaning "knowledge all over", "knowledge", "knowledge and understanding" or "inner knowledge". But in the context of philosophy, the word "philosophy" translated from English as "Philosophy" refers to love in knowledge. Scholars interpret educators as "knowledge", and in essence, there is more to the knowledge and the way to seek knowledge than the knowledge itself. So philosophy is a sense of wonder and ambition about things in the universe, the emergence, the location, and the extinguishment of the phenomenon. There is a hypothesis that the phenomenon that is seen forever is an illusion and that something is above the phenomenon. 


\section{International Journal of Social Science and Economic Research}

ISSN: $2455-8834$

Volume:06, Issue:01 "January 2021"

Philosophers are people who like to think, like to ask. Always is a child to the world, ambition is the emotion of philosophers, the philosophy begins with the ambition and the philosophical knowledge as an open-ended knowledge.

Porn Rattanasuwan (1989) has been described as philosophy meaning good knowledge, or primary knowledge. This word is Sanskrit derived from the word "pra" meaning "truly sublime", "chaya", meaning "knowledge" or "wise", the word "philosophy" means "essential or quintessence knowledge".

TaveePolsompop (2004) gave the meaning "philosophy", meaning "rounder". It's a word that's synonymous with the word "wit". This translates to "knowledge", but the word "intelligence" is a Pali term, what it calls "philosophy" or "intelligence". There must be two characteristics: knowledge and knowledge must match, if the knowledge doesn't match what you know, that kind of knowledge can't be called philosophy or wisdom, but it's called comments only. For example, in thunder and lightning, ancient Thais say that thunder is Rammasoon throwing axes, and the lightning is caused by Mekhala luring the glass. Later, research has shown that thunder and lightning are caused by positive and negative electricity. So that thunder and lightning were caused by Rammasoon and Mekhala, it was not a philosophy. Because knowledge and facts are different, when knowledge differs from facts like this, the answer to that thunder and lightning comes from Rammasoon and Mekkhala, but only as a comment. The answer to thunder and lightning is caused by electricity plus negative electricity. It is classified as knowledge only, the answer to thunder and lightning from positive and negative electricity is that it is organized as knowledge or philosophy.

FeunDokbua (2002) has given the meaning of "philosophy" is the Sanskrit language it comes from the words "Pra + Chaya" meaning "know all over", "know well" and "know good". The term KromMuenNarathipPhongprapan has been used as a term for a subject called "Philosophy" in the west, out of Thailand, it is no longer used. Therefore, telling a foreigner that a philosophy or philosophy course will not understand, even in India, philosophy is not used to call philosophy in Thailand, but philosophy is also referred to as a philosophy, or another term for philosophy is the term "toss", which means "opinion", "see the truth in that regard". The term "Philosophy" comes from "Philos, Love + Sophia, knowledge, ingenuity, love, glory". In all disciplines, whether in the past or the present and the future, and by definition, this, according to the traditional meaning of Greek, all subjects are to satisfy human curiosity, or to feed the mind and nurture the mind, it is a philosophy subject, any subject that is professional, to raise yourself or as a body food is not classified as philosophy. 


\section{International Journal of Social Science and Economic Research}

ISSN: $2455-8834$

Volume:06, Issue:01 "January 2021"

In conclusion, "philosophy" refers to those seeking knowledge that is observed and interested in studying for reasons or evidence to prove the truth based on doubt, which is the basis of science, some scholars say, "philosophy is the mother of science".

\subsection{What is philosophy?}

The philosophy is to study knowledge and truth from all very wide sciences. Therefore, the branch must be digested to make it easier to study, and also to gain knowledge and detailed facts (Carter, V. Good, 1959) which contains the following details:

1. Metaphysics is a study of nature, spirituality, and God, which divides the view of finding truth into:

1.2 Dualism believes that there are two real truths: object and mind.

1.3 Pluralism is considered to be truer than two things: (1) pluralism, the fact that there is a lot of true truth: atomic or atomic, (2) pluralism, it is considered to be made up of atomic or monad.

There are three metaphysical problems: (1) the question of the universe is the answer to the problem of all things in the universe, (2) the hypothesis is the answer to the general state of the universe, and (3) the psychological problem is the answer to the mental problem.

Metaphysics is the first pure philosophy to occur in the world, it arises because of the wonder of ancient humans who have environmentalism, why it is, and how it is, attempts to find out the cause of the possible cause of the suspect and get answers in a somewhat wrong manner, it's a little closer to reality until finally get the complete answer. These movements are metaphysics theory, and metaphysics are considered pillars of the philosophy structure of two pillars, epistemology, if metaphysics lack philosophy, it simply does not. Therefore, to apply philosophy to the philosophy structure, metaphysics are the main. (SumethMethhavitchayakul, 1997)

2. Epistemology or theory of knowledge is a response to four problems with human knowledge: (1) how knowledge looks, (2) how human knowledge comes from, (3) how limited knowledge is, and (4) what criteria are there to determine whether knowledge matches reality?

3. Logic studies the rules of reasoning for the use of valid reasons, logic is a tool of philosophy to analyze ideas, logic, even if it is still considered to be incorporated into philosophy, but be aware that the content is singular and stereotyped, even higher education courses have been segregated into majors (SathitWongsawan, 2000). 


\section{International Journal of Social Science and Economic Research}

ISSN: $2455-8834$

Volume:06, Issue:01 "January 2021"

4. Ethics or moral philosophy is the answer to ethical or evil problems of human action, there are three points: (1) what is the highest value or what is best for mankind? (2) What is the ethical basis? And (3) what is the nature of ethical values?

Ethics is a branch of philosophy, one that studies the value of action or human behavior, whether such actions are good deeds or not, should or should not, ethics is strongly linked to metaphysics concepts because ethics is a guide or practice to reach each level of truth. (Pruitt Boonsritan, 2020)

5. Aesthetics is the answer to a problem about the aesthetic value or beauty of things in the world, what is the beauty of artworks does it exist.

Many philosophical studies, these philosophical reviews, and thorough studies of history, while philosophy was thought up, it give us the scientific knowledge of philosophical thinking. In other words, it is known that the philosopher sought to think of philosophy from emptiness if you think about the mental awareness caused by the environment, how has the environment changed, the philosophy has changed accordingly, there is not a single philosopher who is a free thinker. (SamakBurawat, 2001)

Therefore, it is concluded that all of them are distinctive or focused on different approaches following the framework of the defined philosophy, as well as the general science that studies the characteristics that are featured, such as science, social sciences, and humanities. However, in terms of adoption, it relies on the integration of various fields of philosophy to be applied to formulate concepts, methods of seeking knowledge, and application as appropriate.

\section{Life-long learning}

National Education Act B.E. 2542 (1999) and as amended (No. 2) B.E. 2545 (2002) Section 4, has defined lifelong education as a combination of informal and hospitable education, to be able to continuously improve the quality of life.

SunthonSunnanchai (2005) said that lifelong education is a whole study of human life, from birth to death, the aim of human development to adapt to the changes in today's world and continuously develop to the full potential of each person is an incentive to learn for themselves from both formal and informal learning sources and informal.

SumaleeSangsri (2006) said that lifelong studies mean that all types of studies that occur throughout the life of humans from birth to death are studies aimed at improving individuals to adapt to changes in a person's life and develop them to the fullest. Individual potential lifelong education covers all forms of education, including informal education, and informal education 


\section{International Journal of Social Science and Economic Research}

ISSN: $2455-8834$

Volume:06, Issue:01 "January 2021"

from all sources of knowledge in the community and society, and takes place anywhere without time and place, lifelong education is a life-related study and blends in with a person's lifestyle.

Therefore, in summary, lifelong learning means the development and adaptation or change that occurs in the person as a result of the process of intellectual development, society, and individuals who act continuously throughout their lives, which may be the result of life, learning intentionally or unintentionally, lifelong learning does not only cover adult education but is an education for every stage of life from birth to death, as well as the pursuit of the understanding of others on a global scale. The thinking base of learning consists of learning to coexist Learning to know, learning for practice, and learning to be a complete human being to achieve selfdevelopment and society.

Based on the analysis of the definition of the study, lifelong learning refers to the process of change in thinking, mind, and physical skills. It provides a better way in all phases of lifelong learning. In which the educators are divided into three words "life" or "life". May look in terms of human development, life is growing. There are many changes and factors related to wellbeing, society, environment, religion, and politics. The term "lifelong" or "life span" may be viewed in the moment of life that people are born through experiences from birth to death, and the word "learning" is the process of changing behavior in a better direction than ever before. The concept of lifelong learning as an education strategy was born more than 30 years ago under the efforts of the OECD UNESCO and the Council of Europe, which responded to past shortcomings, while a person learns all the time that he is still alive. Educational opportunities are limited at the beginning of life, dominating formal education programs. Therefore, it is necessary to provide a second chance to those who do not get educational opportunities during childhood and adolescence. Lifelong learning doesn't just mean adult education, but it also covers all forms of learning throughout life. Therefore, lifelong learning management requires a comprehensive view. At present, educational agencies have many policies and strategies that create and encourage people in the country's society. Lifelong learning is distributed through the educational process, it's going to take a long time to reach all the target audiences, but it's not going to be possible. At the same time, social agencies are encouraging the widespread flow of learning, which can be summarized as a guide, as follows: (1) improved access to quality and fairness in learning, (2) build a solid foundation for learning skills, (3) focus on all forms of learning; (4) allocate resources and leverage resources from all sectors, encourage learning to occur at every moment in your life, and (5) create a network of learning partners to cover all sectors.

The goal of lifelong learning concepts in Thailand Ideas considered by researchers based on lifelong education policies and strategies it is known that lifelong learning is the primary goal for all people to be educated. Which education will bring in the right and ongoing learning skills and 


\section{International Journal of Social Science and Economic Research}

ISSN: $2455-8834$

Volume:06, Issue:01 "January 2021"

a combination of lifestyle, this enables individuals to develop in all aspects, whether physically, mentally, and intellectually, at any age. It is the person who can live a normal life according to their potential. It requires morality, ethics, and a culture of living. To have sufficient basic knowledge for the company's operations, the company has It is possible to adapt to situations, or solve problems appropriately, have the ability to continuously seek and enhance knowledge, choose to receive information and apply appropriately, adapt, take appropriate health care and improve their quality of life at all stages of life, and live happily with others.

Another goal of lifelong learning is to focus on distributing equal opportunities in learning. The expansion of educational opportunities alone does not reduce the difference in the quality of life of people in society. Therefore, there are many different forms of learning and can take place in a variety of ways, both from formal courses. For example, in schools or educational institutions, to informal, such as in family, community, and workplaces. For those involved who have the power to manage education and learning to implement lifelong learning strategies, three resources must be taken into account, that is: the first is adequacy, which provides sufficient resources to support different types of lifelong learning throughout each period of age. Secondly, how effectively resources have been used, and third, it's the value of the budget, whether the results are comprehensive learning across all demographic groups.

\section{Concepts of the elderly}

\subsection{Elderly Meaning}

The Royal Thai Dictionary (2003) gives the meaning of the word "old", meaning age with a debilitating age, but the term is not particularly popular among the elderly and academics, because this term causes depression and despair. Therefore, the meeting of the senior group with "Lt. Gen. AttasitSitsytorn" presided over the meeting of the senior scholars, since December 1, 1969 , the term "elderly" has been established. The term is a respected meaning for those who are old and elderly both aged and experienced. Therefore, the elderly refers to those aged 60 and over, this is the age of retirement or retirement based on the calendar criteria agreed by the International organization. Therefore, the age of physical condition changes in the deteriorating condition and also the psychological and social changes that causes the elderly to experience difficulties in their lives, whether it's physical health, mental health.

As well as the economy, care from families, children, and government agencies must be needed to provide better living and quality of life for the elderly.

\subsection{Importance of seniors and policies concerning the elderly}




\section{International Journal of Social Science and Economic Research}

ISSN: $2455-8834$

Volume:06, Issue:01 "January 2021"

The elderly are valuable and important to society because in addition to being dependent on the child's mind it is also respected by people in their family. The elderly will also be regarded by society as experienced, thoughtful, and have done the benefits of society when they are at work. The government in the period of "General PremTinsulanonda" recognizes the importance of the elderly and the problems that may arise. Therefore, the cabinet passed a resolution on December 14, 1982, approving the date of April 13, every year as an elderly day. This is because of the increase in the number of elderly people and the problem of the elderly. As a result, the government is aware of the importance that the elderly should be prepared in various cases. The policy was established in the 5th National Economic and Social Development Plan (1982-1986). The Cabinet appointed the National Seniors Committee on February 9, 1982, and appointed the Minister of The Interior as Chairman; it is responsible for preparing long-term plans for the elderly (1982-2001). The 6th National Economic and Social Development Plan (1987-1991) states should play a role in understanding the problems of seniors aged 60 and over, it also encourages people to plan or prepare for self-sufficiency at an age. For the 7th National Economic and Social Development Plan (1992-1996), the state has a policy of encouraging the elderly to have insurance for public health services, in terms of prevention, health promotion, and medical care. One important activity is that in 1992, the Institute for Health and Geriatric Medicine was established as an agency that fulfilled government policy, the company provides medical relief to the elderly (the elderly receive a medical relief card thoroughly). Later, in 1994, the state has a policy on the elderly in terms of providing the well-being of the elderly to live happily in society, and according to the government's policy, the next seven years are aimed at providing the people of the country with good health, namely, health and wellness in 2000, which is the main social goal. Therefore, the government aims to promote the health of the people, it focuses on older people. The Ministry of Health and other related agencies, therefore, provide the promotion of health and welfare of the elderly, encourage the elderly to play a role and value the knowledge or experience that the elderly have accumulated throughout their lives, if it is passed, it benefits both the elderly and the society. It also encourages communities and society to play a role in collaborating to develop and help the elderly. (JirandornWicksungnoen, 2010)

Therefore, it concludes that the elderly are the ones who play a role and are important to society, from small societies to family, community societies, as well as large national and global societies, because of their livelihood as an elderly person, not in vain. The elderly are experienced, so they can be everything they want to be, especially when they are supported and promoted in various areas, giving the elderly the potential to live happily and become a more valuable precursor.

\subsection{Role of the elderly}




\section{International Journal of Social Science and Economic Research}

ISSN: $2455-8834$

Volume:06, Issue:01 "January 2021"

An important role for the elderly is to help train and teach young children in matters of morality, history, social and cultural traditions, and they can adjust their roles to be respectful or have good imagery. The elderly should think of themselves as a resource of family and community, on the other hand, families, and communities should think the same. However, in developing countries, aged care services are also managed systematically, if the elderly adjust their role as a family, it will be good for the family to be united. Sending elderly people to care facilities is seen as uncommon in both family and elderly. The elderly can help resolve tensions and conflicts within the family using long-standing experience, as well as dealing with crises, this can play a positive and cognition-based role, the elderly can be economic activists by producing goods and services, this will increase the number of producers rather than those who are burdened, this can bring income and give something to the family, adding value to yourself. As well as looking at selfportraits in a positive direction. (JirandornWicksungnoen, 2010) The elderly continue to play a role and importance in society, respected and reliant on their children and relatives, because the elderly have been through a lot of life and their work experience, despite the deteriorating physical condition, the role of society as an experienced person and by benefiting society for a long time should be praised for its sense of value and stability in society and the environment.

\subsection{Problems of the elderly}

The problem for the elderly is mainly due to changes in the elderly, namely physical changes. Psychological and emotional changes and social changes can result in changes in physical fitness, mental health, economy, society, and culture. This causes many problems, namely health problems caused by the deterioration of the system, making it unhealthy, it's easy to get sick and sick. This affects the mental and emotional health of the elderly and social changes such as loss of social fitness and job function, family problems, social problems, and economic problems, the problem affects the elderly both directly and indirectly.

\section{Lifelong learning concept for the elderly}

The direction of sustainable development for the elderly in Thai society was also achieved at the workshop. In November 2015, participants discussed five scopes of competencies for AsiaPacific, that is to say, (1) adaptation and reduction of climate change (2) citizen's literacy (3) global citizenship (4) digital literacy, and (5) work and livelihood. In September 2016 workshop, 2 domains were added, include, (1) health and well-being, and (2) culture and identity. It is important to note that the basic capabilities will cross the capacity in various areas to sustainable development as shown in figure 2: 
International Journal of Social Science and Economic Research

ISSN: 2455-8834

Volume:06, Issue:01 "January 2021"

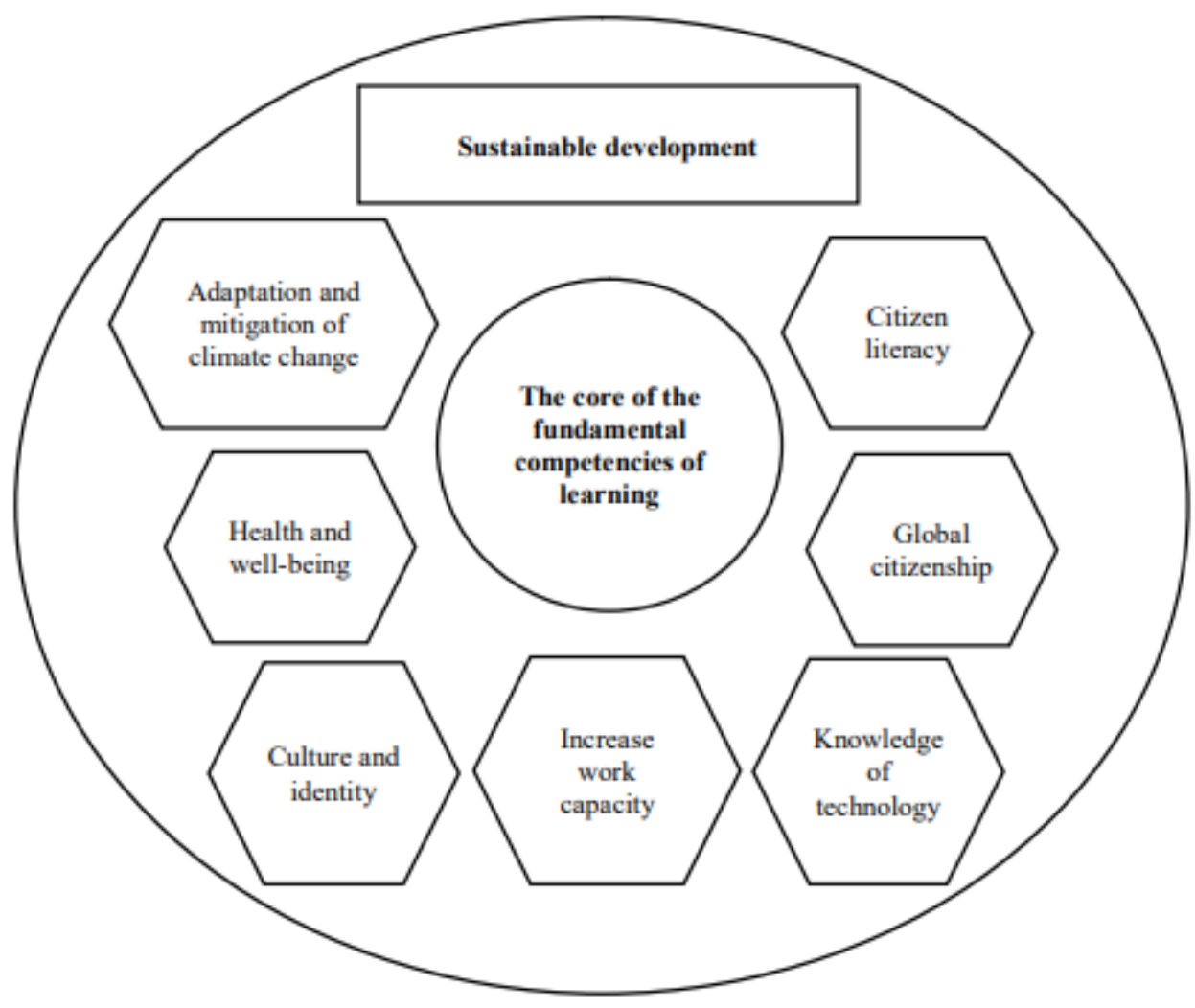

Figure 2: Show the sustainable development process.

Source: Synthesis-Asia Pacific Competency Framework (2016)

Based on the data model two above, we can analyze the sustainable development process that is the goal and need to develop all dimensions of the world, which focuses on the seven pillars of basic learning performance:

1. Adaptation of climate change reduction is an important and necessary priority of sustainable development, and adapting human changes to the economy, society, and the environment for a normal existence, happiness, and access to nature, and the methods that need to be learned to manage existing or environmentally friendly natural resources to reduce climate change.

2. Health and well-being are also important an issue that all sectors will work together to develop what has been the initial impact since the four factors, is a food that is adequately consumed, appropriate apparel according to the climate and society, housing that is consistent with the safe lifestyle, and the risk of conventional health to affect well-being means a good quality of life.

3. Culture and identity are the ones that support individuals and communities, as well as society, and the country to have solidarity together because they are spiritual nurture for their members to 


\section{International Journal of Social Science and Economic Research}

ISSN: $2455-8834$

Volume:06, Issue:01 "January 2021"

be proud and nationalistic. Also, identity will result in a fusion of energy and enormous power to connect other dimensions. For example, education, economy, society, religion, and beliefs, for example, to have a sense of mutual good pride, is also a patron for sustainable development.

4. Increasing productivity is a very important factor in the development of all dimensions because work is a human invention that will create a lot of things that contribute to the life of the sedentary life. All kinds of work can benefit themselves and others. If the public doesn't work, not creating jobs and increasing productivity will be a huge burden and a barrier to selfdevelopment, the community, society, country, region to the world.

5. Technology knowledge is the ingenuity that humans have invented to facilitate and reduce the cost of using natural resources, as well as time and cost of thought and dedication to lighten. The indicators of developing countries rely on state-of-the-art technology to facilitate the success of their work and the activities of almost everyday life, which is inevitably relevant to the sedentary lifestyle of everyone.

6. Global citizenship is an important mental building that many may be overlooked and inconceivable, for reasons that each day is committed, but they make a living and make their careers until they have no time to think, global citizenship here means doing what it takes to respond to sustainable development internationally, from small points in everyday life, such as acting in a way that will bring prosperity to life and society as a whole, expanding across all channels to be globally and constructively and well-known.

7. Citizen literacy is another issue that needs to be realized and important because of the communication of human beings of all races, religion, language, need the knowledge to communicate and learn and convey a valuable heritage culture, literacy is a mechanism that creates the limitless power of ideas and intelligence of citizens that will be a cog in the development of the potential of the public.

Therefore, if the general public or the elderly have created and developed themselves with these seven attributes, it will be an important part of the knowledge that will lead to lifelong learning and to achieve the will of the Asia and Pacific region. This can be concluded that lifelong learning for the elderly can be concluded. The results are based on preliminary studies, as well as social and environmental factors that are appropriately combined to deliver results such as wellbeing and good health, the family is warm. This is consistent with sustainable development that relies on the pillars of basic fitness of learning with these seven elements. It, directly and indirectly, affects the elderly as a guide for lifelong learning for general quality of life.

\section{Methodology}


International Journal of Social Science and Economic Research

ISSN: 2455-8834

Volume:06, Issue:01 "January 2021"

This research is qualitative research by collecting data through document review methods, related research, in-depth interviews, and focus group discussion.

\section{Research scope}

\subsection{Scope of content}

Documentary Studies conducts studies and synthesis of information from documents and conceptual evidence. The researchers, theories, and related research reports include documents, books, and research reports, based on concepts, concepts, and theories about the philosophy of living with the elderly and lifelong learning. Qualitative Research collects data from in-depth interviews and focuses on group discussions, about the philosophy of learning of the elderly for lifelong learning.

\subsection{Population and sample boundaries}

The population and examples in field studies to know the philosophy of elders for lifelong learning, there is a study process. The researchers selected samples, with the reserve name, name, and position of duty, to protect basic rights using a fictitious name instead.

1) Conduct studies and select examples of elderly people, policy-related individuals, and people associated with the elderly in a specific way (Purposive Sampling) according to the importance of the subject, namely, the person involved with the elderly in Lampang province, in-depth interviews in 16 provinces, a total of 48 people.

2) Conduct studies and select examples of elderly people, policy-level individuals, and those associated with the elderly purposive sampling according to the importance of the subject, namely as individuals who are involved with the elderly in Lampang province, focus group discussion in 10 provinces for a total of 30 people, this is as follows:

3) Conduct analysis, synthesis, a summary of research results and recommendations based on documented information, in-depth interviews, and focus group discussions.

\section{Research tools}

The creation and development of research tools and research operations focus on the collection of data from documents, research, in-depth interviews, and focus group discussions. The analysis and synthesis of the data focus on how to seek knowledge, from setting up questions consistent with research issues (ChedthaphumWanpaisan, 2019) using key tools: (1) In-depth Interviews, and (2) Focus Group Discussion. 


\section{International Journal of Social Science and Economic Research}

ISSN: $2455-8834$

Volume:06, Issue:01 "January 2021"

However, In-depth interviews and focus group discussions have been considered and guided by five experts who are knowledgeable, capable, and skilled, and experienced concerning research and activities of the elderly.

\section{Information collection}

The research team used the self-collecting method to obtain the data according to the purpose of the study, as follows:

1) Interview the researchers conducted in-depth interviews for the elderly, policy-level individuals, and 48 related persons.

2) Focus group discussion for seniors, policy individuals, and 30 elderly persons.

\section{Data analysis}

Documentary Research and Empirical Information, both in-depth interviews and focus group discussions, is a qualitative research process. The researchers analyzed the data according to the following steps:

1) Qualitative data analysis focuses on analysis based on the material aspects of the content defined by the content analysis by the topic, namely, meaning, concept and philosophy theory, lifelong concepts and theories and theories concepts and theories about the elderly Lifelong Learning Concept for Seniors National Senior Strategy No.2 (2002 - 2021) situation of seniors in Lampang, Lamphun and Phrae, and related research.

2) An interview on the philosophy of learning of the elderly for lifelong learning is a qualitative analysis of data, focus on analyzing data from interviews that collect data from samples. The study was conducted to analyze the data, as follows: a complete selection of interviews in response to descriptive analysis, part one is an interview about the general information of the sample, part two is about the philosophy of living for the elderly for lifelong learning, it is expressive and subjective, and the interview part three is an additional comment.

3) Use qualitative analysis of data to synthesize personal basic data factors with opinions on the learning philosophy of the elderly for lifelong learning.

4) Qualitative analysis Use the remix by descriptive, based on the information consistent with the information from the interview. In-depth interviews, the researcher's group data grouping based on the essence of the interview issue, and then synthesize the content analysis technique. It conducted in-depth interviews of 48 people and 30 focus group discussions. There are important 


\section{International Journal of Social Science and Economic Research}

ISSN: $2455-8834$

Volume:06, Issue:01 "January 2021"

issues related to the philosophy of living of the elderly for lifelong learning in Lampang, Lamphun, and Phrae province.

5) To summarize the findings, the philosophy of elders' livelihoods is to provide lifelong learning as a confirmation that is consistent with the facts and as appropriate.

\section{Results}

In this research, qualitative research is conducted in this chapter, conducted in-depth interviews. About the philosophy of living for the elderly for lifelong learning, the five aspects are summarized as follows:

\section{Truthful Living Philosophy (Metaphysics)}

1.1 The elderly had the principles of daily consumption. Overall, it was found that there were two characteristics which can be summarized as follows.

Appropriate manners, the elderly choose a nutritious and beneficial diet for the body, follow the principles 6 Aor. namely, (1) exercise (2) diet (3) mood (4) disease-free (5) environmental health (6) abuse (Interview with Mr. R. Name fictitious October 19, 2018), housing providing comfort, peace, cleanliness, proper nutrition, near and not far from the housing (Interview with Mr. S. Name fictitious on 19 October 2018). The principles of daily consumption practice include knowledge, mainly due to the effective self-fulfillment of community leaders or people who are influential in the idea of persuading consumers and adhering to government principles, from a specific person who knows what is about the consumer (Interview Mrs. H. Name fictional October 26, 2018). Most elderly people are 100\%, and they are used in a daily life that has been used in several health care companies, for example, from the Hospital for Health Promotion, and the village health volunteers of each group (Interview Mrs. DD. Name fictional October 19, 2017). The elderly are primarily in the practice of consuming consumer goods in everyday life, taking into account the exploitation of what they want and using what is available that may be deteriorating or depleted, to meet the needs of themselves and their families (Interview Mrs. CC. Name fictional October 19, 2018). Eating folk food, especially naturally grown kitchen vegetables, will help to stay healthy and live longer, as well as prevent chronic diseases (Interview Monk B. Name Fictitious 201821 October 2018).

The most inappropriate behavior is that the elderly often do not follow the principles 6 Aor. If you choose a simple, easy-to-chew, and regularly eaten food, or some people may be fed or less likely to eat (Interview Mrs. W. Name fictional October 20, 2018). There is an inappropriate consumption due to the habit of consuming it since childhood, working-age, along with the 


\section{International Journal of Social Science and Economic Research}

ISSN: $2455-8834$

Volume:06, Issue:01 "January 2021"

environment, lifestyle, and the traditions of the local area used to be consumed. As a result, there is inappropriate consumption. (Interview Mrs. X. Name Fictional October 20, 2018)

1.2 Elderly There are practices for participating in social and cultural activities. Overall, it can be summarized as follows: the elderly should be volunteering activities, caring for each other, and helping society by performing public service to the city (Interview Mr. A. Name fictional October 25, 2018). The elderly as a whole are thought to participate in social and cultural activities because they are lonely or depressed, just meeting and talking to people will make them happy (Interview Mr. B. Nam fictional October 25, 2018). The elderly group code of association may be due to the needs of the elderly, from the core, expand into large groups and become social and cultural leaders in the community (Interview Mr. L. Name fictional October 25, 2018). Participation in the activities of the aging person will be performed according to their capacity with satisfaction and must not exceed their abilities (Interview Mr. C. Name fictional October 27, 2018). Overall, the elderly group will participate in the activities by persuading each other to participate in the activities of the temple, the sub-district administration organization, such as the elder school, the participation of the elderly, to promote mental health, to be healthy and clear, etc. (Interview Mrs. DD. Name fictional October 19, 2018). Social and cultural activities will be attended by village activities, where the activities of the temple are if they are strong seniors. It's easy to drive around and you'll be able to get to these activities more often than the elderly who have to wait for their child to drop off (Interview Monk A. Name fictional October 25, 2018). The elderly need to be ready in many ways, such as being strong enough to work out, the family must be ready, the important thing is to have a volunteer, etc. (Interview Mr. D. Name fictional October 26, 2018). Most elderly people are most involved in religious activities; the second is the social and cultural activities of the community (Interview Mr. E. Name fictional October 27, 2018).

\section{Knowledge Living Philosophy (Epistemology)}

2.1 Consumer knowledge philosophy it found that the elderly are consuming as important and necessary for their livelihoods. It found that the elderly studied the correct consumption and consumption. Most elderly people have been cultivating their beliefs for a long time (Interview Mrs. F. Name fictional October 26, 2018). The elderly are a good example in the community, where routine conduct is an example for young people to see the action of life because if they behave badly, they will not be good in the community (Interview with Mr. U. Name fictional October 20, 2018). Learn from modern technology; keep up with the current world on Facebook or Line to find useful information on how to live a sufficiency economy (interview Mr. R. Name fictional October 19, 2018). General knowledge about good housing affects physical health and kindness, good food is beneficial to the body, and near-home hospitals can quickly solve the disease (Interview Mr. S. Name fictional October 19, 2018). The elderly are consumed only by 


\section{International Journal of Social Science and Economic Research}

ISSN: $2455-8834$

Volume:06, Issue:01 "January 2021"

lifestyle, which may include healthy food and beverage groups, as well as medicines and supplements for better health (Interview Mrs. W. Name fictional October 20, 2018). The consumption of the elderly is important and essential for health care awareness, eating healthy herbs can have a positive or bad effect on the elderly, this can be used or as information to continue to make consumer decisions (Interview Mrs. DD. Name fictional October 19, 2018). Some elderly people are knowledgeable in the field of consumption, from the introduction and training or media which can be applied in everyday life (Interview Mrs. M. Name fictional October 20, 2018). To survive in society consumables are essential and very important because they can meet their needs, for example, when hungry they need food or may think of the necessity, usefulness in various uses in everyday life (Interview Mrs. K. Name Fictional October 26, 2018). The elderly have the highest physical needs to meet the need, include four-factor requirements and medical needs (Interview Mrs. Ab. Name fictional October 26, 2018).

2.2 The elderly have access to social and cultural activities. It was found that the elderly participated in religious activities to help the Buddhist sect to live in Thailand, join the relaxation activities to reduce stress, and enjoy exercise activities to maintain their health (Interview Mr. V. Name fictional October 21, 2018). The elderly have helped society, make a precious living, and are proud to have the opportunity to help society when life is worth living in peace (Interview Mr. Ac. Name Fictional October 27, 2018). Participation in social and cultural activities is important because it allows the elderly to talk to the same generation, or have the opportunity to engage in activities that are interested in and have the aptitude to convey the wisdom of the villagers to future generations (Interview Mr. Q. Name fictional, November 16, 2018). Social activities are that the elderly play a much-needed role and need to live, the elderly must be a role model for participating in traditional and religious activities (Interview Mr. L. Name fictional October 21, 2018). The elderly still need to participate in society, want acceptance and participation in activities to build relationships in the community (Interview Mr. D. Name fictional October 27, 2018). Participation in social and cultural activities of the elderly is necessary, as the elderly have the opportunity to participate in the activity, they will be able to gain knowledge from the activities to adapt to their livelihoods (Interview Mr. Ac. Name Fictional October 27, 2018). Participation in social and cultural activities of people of the age is not yet available, as participation in activities such as the need for pick-up and drop-off and vehicle requirements, etc., which may sometimes participate or do not participate (Interview Mrs. G. Name fictional October 27, 2018). The elderly, who participate in social and cultural activities, are considered profitable to live and see the wider world without the need to travel but can be harvested from social activities, it makes the elderly feel valued and accepted by society. (Interview Mrs. CC. Name fictional October 21, 2018).

\section{Reasoning Philosophy of Life (Logic)}




\section{International Journal of Social Science and Economic Research}

ISSN: $2455-8834$

Volume:06, Issue:01 "January 2021"

3.1 Rational philosophy on consumer It found that the elderly have reasonable, accurate, and appropriate channels of awareness about consumer principles. It was found that what the elderly should do alongside consumerism is to organize training to increase their potential, knowledge, fitness activities, and recreation of dance (Interview Mr. R. Name fictional October 19, 2018). Important information is obtained from general journalism because it is convenient in the modern era by training according to the convenience of organizing different periods and opening up opportunities for expression (Interview Mr. S. Name fictional October 19, 2018). For example, the channels presented on TV each day, medical hospital channels, and specific knowledge of social media channels such as Line, Facebook, YouTube (Interview Mr. C. Name fictional October 25, 2018). The elderly must have the knowledge and consumer principles, the province must take care and assist with life fundamentals such as wheelchairs and walking sticks (Interview Monk A. Name fictional October 27, 2018). Nowadays, there are many things that the elderly can access, such as on TV, Online Media Application line, Facebook, which contains true and false news, which requires judgment to obtain information (Interview Mr. AA. Name fictional October 19, 2018). The channels for the awareness of the elderly group can be divided into groups, such as the elderly who participate in the activities, the elderly who did not participate in the event may not receive such news or from medical treatment (Interview Mrs. DD. Name fictional October 19, 2018). Channels of awareness about the consumption of the elderly if the elderly persons participating in the activity, such as being in an elderly club, they will receive training, if it is a general age, it is recommended by a doctor (when illness) (Interview Mr. Q. Nam fictional November 16, 2018). In today's days, audiovisual technology, communication, and the elderly learn about consumerism on-demand on radio, television, and publications, it can be rational and comparable to decision-making (Interview Mrs. N. Name fictional November 16, 2018). There are a variety of channels that can be used according to the product's suitability, namely social media, line, which selects channels for the elderly to use the experience to shop and focus on health (Interview Mr. P. Name fictional November 16, 2018).

3.2 The philosophy of reasoning in society and culture has found that the elderly are engaged in thinking, making decisions, solving problems, making good decisions, and rationalizing rather than using emotions (Interview Mr. E. Name fictional October 20, 2018). The elderly create benefits, make society and community peaceful, people in society have a positive attitude to life and help solve social problems (Interview Mr. S. Name fictional October 19, 2018). Cultural and social awareness must be given to the elderly to participate in certain activities on occasions, traditions, or important religious days (Interview Mr. U. Name Fictional October 20, 2018). Social activities such as joining groups of elderly people on the day of the event and frequent training, nibble until participating in the event on the big religious day (Interview Mrs. W. Name fictional October 20,2018). Awareness channels about participating in social activities may be such as solicitation talks, community voice publicity, invited to participate in the event, some 


\section{International Journal of Social Science and Economic Research}

ISSN: $2455-8834$

Volume:06, Issue:01 "January 2021"

elderly people are interested in participating in the activity on their own voluntarily (Interview Mr. Q. Name fictional November 16, 2018). Channels for participation in social activities from the persuasion of elderly groups or public relations announcements from the community, to organize activities or invitations to participate in activities (Interview Mrs. X. Name fictional October 20, 2018). Participation in social and cultural activities of the elderly there are many channels, starting with the favorite and satisfied to participate in the activity, join the activities with the local community to help each other, use the wisdom of the villagers to help develop, learn more about honest occupation, which is a way to participate in social activities to be full of pride and appropriate (Interview Mr. Ac. Name Fictional October 25, 2018). Nowadays, each elderly community has a social network with a need for integration, to participate in social activities that will vary according to the needs of the elderly, which is the right channel (Interview with Mrs. N. Name fictional November 16, 2018).

\section{Philosophy of living virtue (Ethics)}

4.1 The elderly have a moral concept of consumption, it was found that the elderly know how to calculate the amount of consumption that contributes to or causes blame, know-how to meet their needs, know their volumes, and know the valuation that may be you or blame (Interview Mrs. $\mathrm{Z}$. Name fictional October 19, 2018). There is a perception from elderly people with community experience. There is an analysis of the negative effects on people in the community (Interview Mr. T. Name fictional October 19, 2018). The elderly are examples of goodness, a good example of society (interviews, Mr. U. Name Fictional October 20, 2018). Learn about the characteristics of items that you want to use to be consumed or consumed as a basis for decision-making, if you've used them, how much satisfaction you're going to be (Interview Mr. I. Name fictional October 21, 2018). In the elderly, more awareness of consumption, including health and medical care, and the need for good care from their children (Interview Mrs. Aa.Name fictional October 21, 2018).

4.2 The elderly have a moral concept of society and culture. It found that the elderly relied on knowledge and experience that required intelligence and consciousness to know and understand, social and cultural goodness and that the elderly must be rational (Interview Mr. V. Name fictional October 21, 2018). Elderly people who have the skills to participate in social activities, that person will be proud. This enables others or society to develop good things and media and to effectively bring together other people's potential to develop society and the nation (Interview Mr. I. Name fictional October 21, 2018). The family is considered to be the closest society to the elderly, receiving love and gratitude from children is the basis above from society (Interview Mrs. Y. Name fictional October 21, 2018).

\section{Beauty Living Philosophy (Aesthetics)}




\section{International Journal of Social Science and Economic Research}

ISSN: $2455-8834$

Volume:06, Issue:01 "January 2021"

5.1 The philosophy of beauty on consumer It found that the elderly can use it in everyday life to be happy, elderly people who regularly practice prayer and practice morals can be like medicines, when mental health is strong, physical health is also good (Interview Mr. R. Name fictional October 19, 2018). Knowing to choose a safe place to live, knowing how to eat food, and knowing what makes your body, mind, and mind are conventionally happy (Interview Mr. S. Name fictional October 19, 2018). The elderly have the knowledge and skills to work, such as sewing machines, as well as household beauty, and if it is expressed, it will make the elderly happy to do so (Interview Mr. U. Name fictional October 20, 2018). The transfer of experience and wisdom from the habituation that has been practiced by the children passed on to each other becomes a consumer routine (Interview Mrs. W. Name fictional October 20, 2018). The elderly will have good knowledge or skills in consumption. It has been used since one of the days of modernism, also known as tradition, or with the wisdom of the villagers to apply for a balanced life (Interview Mrs. EE. Name fictional October 19, 2018). Skills and skills that apply to everyday life if you have the skills and ability to use the consumer, it will make the lives of the elderly happier, if you know the word modest, diligent, self-reliant, you can be satisfied with what they have, there is generosity to each other, it is in a happy society (Interview Mr. L. Name fictional October 21, 2018). It is used to eat and use with the highest value and quality (interview Mr. A. Name fictional October 26, 2018).

5.2 Philosophy of beauty in society and culture it was found that the elderly showed off their dance or musical performances by volunteering to help with various tasks, which is considered to be a contributor, and they are happier than the recipients (Interview Mr. R. Name fictional October 19, 2018). Experience teaches how to think, know how to act, assess value, and understand how to behave, this is an activity that is good for people in that society, and most social activities are focused on people of the same level or similar age (Interview Mr. T. Name fictional October 20, 2018). The elderly have many knowledge and wisdom, allowing them to express themselves socially and culturally, as well as the traditions of the community (Interview Mr. U. Name fictional October 20, 2018). The elderly are capable and have the potential of them, health, family, property, in the time side, it is found that the elderly, if they are ready, will have a better time to participate in social activities (Interview Mr. O. Name fictional November 16, 2018). The potential for elderly people and their family well-being, as well as the wealthy and physical city, will be more likely to participate more often than those of the age to find themselves and their families in the group (Interview Mrs. DD. Name fictional October 21, 2018). The ability to participate in activities it was found to be based on the potential of each elderly person, people who are ready to participate often have the opportunity to participate, but if you are an old person who has to work for him, it is difficult to find opportunities to participate in activities (Interview Mrs. X. Name fictional October 20, 2018). The elderly have the skills to participate in social activities, which will be a pride that allows others or society to develop what 


\section{International Journal of Social Science and Economic Research}

ISSN: $2455-8834$

Volume:06, Issue:01 "January 2021"

we convey and can bring to the potential of others to develop society and the country effectively (Interview Mrs. H. Name fictional October 21, 2018). The elderly have a feeling that they are valued, love, and cherish the community, which is their own thing. As well as having love and care for the public domain of the community, as well as being an advisor to various organizations in the community (Interview Monk B. Name fictitious October 21, 2018).

\section{Discussion}

1. The philosophy of living truth (Metaphysics) on consumer and social and cultural aspects it was found that elderly choose foods that are valuable and beneficial to the body, by following principle 6 Aor, that is: (1) exercise (2) diet (3) mood (4) disease-free (5) environmental health (6) abuse, comfortable housing, calm, clean, food was characteristic, there is no near medical place, not far away from housing, there are three principles in daily consumption operations, that is: (1) self-fulfilling beliefs for a long time effectively, (2) have people who are famous in the community/people who influence today's persuasive thinking, and (3) adhere to government principles. From the specialized knowledge of that, the elderly tend not to have a complete diet. However, the elderly will choose a simple meal and a regular meal, or some people will be anorexic and will eat less, most elderly people are used to everyday life that they have seen and experienced on their own, it will be provided following the advice of health professionals. Such as the hospital in the sub-district in the village and village health volunteers, etc. It is trusted by the advice of polite care in terms of consumption and consumption. There is an inappropriate consumption due to the habituation that has been consumed since childhood and working age, as well as the environment, lifestyle, and local traditions that used to be consumed. As a result, there is inappropriate consumption. The elderly are primarily in the practice of consuming consumer goods in everyday life, taking into account the exploitation of what they want and using what is available that may be deteriorating or depleted, to meet the needs of themselves and their families, eating folk foods such as naturally grown home-grown vegetables helps to stay healthy and prevent chronic diseases, for the elderly, there are practices for participating in daily social and cultural activities. Overall, we found that volunteer activities should be used to help each other and to help society, by public service to the city. The elderly as a whole are thought to participate in social and cultural activities because the elderly if they are home, will only experience loneliness or depression, if the elderly have a lot of meetings with people, it will make the elderly feel happy. The elderly group code of conduct in the form of elderly clubs, associations may be due to the needs of the elderly. In the participants' community, the participants of the age will perform activities based on their capacity with satisfaction and must not exceed their abilities. The elderly have the principle of participating in social and cultural activities in the community or village, talk to the temple and the sub-district administration organization or sub-district municipality. Such as school, elderly, etc. participation of elderly 


\section{International Journal of Social Science and Economic Research}

ISSN: $2455-8834$

Volume:06, Issue:01 "January 2021"

people to promote mental health and wellbeing social and cultural activities will be attended by village activities, and temple activities, if you are a strong elderly person and drive on their own, they will be more frequent than the elderly who have to wait for their children to take part in social and cultural activities. Which, in the daily life of the elderly, the family must be ready, the family must be ready, the mind must be volunteered, most elderly people are involved in religious activities, and the second is the arts and cultural activities of the community, etc.

2. Philosophy of life of knowledge (Epistemology) on consumption and social and cultural aspects It found that the elderly have studied modern technology in the current world, playing line, Facebook, YouTube, for useful information on how to live a sufficiency economy, (1) good housing, healthy, benign, (2) good food is beneficial to the body, and (3) closer hospitals to solve disease problems quickly, consumption and accurate consumption are very important. Most elderly people have been cultivating faith for a long time, the elders are a good example in the community, and routine practices provide an example for young people to see how poor daily life is, making them poor in the community, with the elderly having only the consumption necessary for their lives. There may be healthy food and beverage groups, as well as medicines and supplements for better health by the consumption of the elderly. This is important and essential for the awareness of health care, such as eating healthy herbs, which can have a positive or unhealthy effect on the elderly, can be applied or as information to continue making consumer decisions. Some elderly people know consumer services, from the introduction, training or media that can be applied in everyday life to live in a society where consumerism is essential and important because they can meet their own needs, such as when they are hungry, need food, or think of the necessity of social use. In everyday life, there are the highest physical needs to meet the need, including four-factor requirements and medical needs. The elderly have access to social and cultural activities that are important and necessary for life, it was found that participating in religious activities help the elderly in Thailand and participate in recreational activities in case of stress relief, exercise activities, in case you take care of the health of the elderly, make life precious and be proud to have the opportunity to help society. When life is socially valuable, the elderly must have the opportunity to talk to the same generation or have the opportunity to engage in activities that are interested in the interests and are good with the people in society, and to convey the wisdom of the local people to future generations. The elderly play a much and essential role in life, the elderly must be a role model for participating in traditional and religious activities. The elderly still need social participation and need acceptance, as well as joint activities to create relationships in the community. It is important to take advantage of the social and cultural activities of the elderly because the elderly do not have the opportunity to participate in the activity, the elderly who have the opportunity to participate in the activities will be able to learn from the activities to adapt to their livelihoods, participation in social and cultural activities of people of the age is not necessarily necessary for life. To participate in activities, there must 


\section{International Journal of Social Science and Economic Research}

ISSN: $2455-8834$

Volume:06, Issue:01 "January 2021"

be an opportunity to participate in activities that may sometimes participate or do not participate in social and cultural activities, be considered profitable in living, and see the wider world without the need to travel. However, it can be harvested from social activities and cultural adherents will be very supportive of physical health and a good mind. It makes the elderly feel valued and accepted by society.

3. Reasoning philosophy of life (Logic) about consumer and social and cultural aspects it was found that what to do in conjunction with consumerism requires training to increase the potential and knowledge of the physical activity, recreation, dance, and journalism throughout the general public. The convenience of the modern era is the ease of organizing the channel to be expressed, the channels presented on daily TV, medical hospital channels, to educate only media channels such as Line, Facebook, and YouTube. The elderly must have the knowledge and consumer principles, rational and social development, and human stability. The province must take care of and assist with life fundamentals such as wheelchairs, walking sticks, etc. Nowadays, there are many things that the elderly can access, such as TV, and online media, which is true and false news. Therefore, it is necessary to use the judgment to receive information on the channels of information about the consumption of the elderly groups such as seniors participating in activities can be received to receive news. The elderly who did not participate in the event may receive such news from the medical facilities. The company has been able to channel awareness about the consumption of the elderly. However, if the group participates in activities such as in the elderly club, they will receive training, if it is an elderly person, it will be recommended by a doctor (when painful) or the district health promotion hospital when going to receive drugs for examination, which technology for communication is now more modern. The elderly can also consume their groceries according to their needs, in radio, television, publications can be rational and comparable to decision-making, with a wide range of channels that can be used according to the suitability of the product, social media, which selects elderly will use their purchasing experience and focus on health.

For the elderly, there is a channel of awareness about participating in social and cultural activities in a rational, accurate, and appropriate manner, it found that let everyone join in the decision-making and solve the problem by making good judgments. Uses reasoning rather than using emotions to create benefits, making society and communities peaceful, people in society have a positive attitude to life, to help solve social problems, the need to recognize the culture and society for the elderly to have the opportunity to participate in certain activities in traditional or religious occasions to participate in social activities. For example, joining a group of elderly people on a day held and training every month, participating in activities on religious day awareness channels about participating in social activities can be channels such as talking, persuasion, publicity, voice stories along the lines of the community, invitations to events are a 


\section{International Journal of Social Science and Economic Research}

ISSN: $2455-8834$

Volume:06, Issue:01 "January 2021"

great activity, and on the other hand, some elderly people are interested in participating in voluntary self-activities, channeling participation in social activities, from the persuasion of the elderly group or the public relations announcement from the community. There are several ways to organize activities or invitations to participate in social and cultural activities of the elderly. This is starting to be a favorite and satisfied to participate in such activities, participants in local communities may be able to help each other and use local wisdom to help develop, studying knowledge and fulfilling a good career is a way to participate in social activities to be fully and appropriately engaged. Nowadays, each elderly community has a social network with a need for integration; to participate in social activities will vary according to the needs of the elderly, which is the right channel.

4. Philosophy of living virtue (Ethics) about consumer and social and cultural aspects It is found that the elderly see that everything on earth is uncertain. The idea is to calculate the amount of consumption that produces benefits, which is to determine how to meet their needs and know the amount of self, as well as the perception of elders with community experience. The elderly are examples of goodness and exemplary society, most elderly people have health problems. The perception of information is also likely to be in healthcare and treatment, as well as consumer health. It's about how accurate the information is, how accurate the information is, how much information is available, but the channels or perceptions that work well are if they have faith and apply knowledge to themselves. Such as the doctor's advice on the introduction of self-care practices for the elderly, etc., the awareness channels of the elderly need to be more diverse, but the result is to believe and put it into practice. The doctor recommends that the doctor study the characteristics of the objects they want to be consumed or consumed. How does it be used as a criterion for judging if used and used for how much satisfaction is used? In the elderly, there is growing consumption of health and medical care and the need for child care.

For the elderly, there is a concept of social and cultural science, found out it was fictional, only wisdom and consciousness are needed, what's going to happen, like social care? If anything, cause problems for the society for solving problems, it requires social processes to solve common problems, for example. Social and cultural aspects, the elderly must be rational, pondering wrong. The participation of most social and cultural activities of the elderly is likely to come from persuasion in groups or according to traditions, cultures during that period, so more media-based publicity should be made. Nowadays, some seniors can play line, Facebook, YouTube, and can quickly persuade and send information to the elderly group, communicate in participating in social and cultural activities it is found that some older people play Line, Facebook, YouTube, and can quickly send information to a group of friends. The elderly, who have the skills to participate in social activities, will be proud to develop in the media and to effectively bring together other people's potential to develop society and the country. In part, the 


\section{International Journal of Social Science and Economic Research}

ISSN: $2455-8834$

Volume:06, Issue:01 "January 2021"

family is considered to be the closest society to the elderly, receiving love, gratitude from children is the basis for it.

5. Aesthetic living philosophy (Aesthetics) on consumption and social and cultural aspects, it found that elderly people regularly pray and practice morals as a result of their mental health and their impact, physical health will also be good, knowing to choose a safe habitat to know how to choose from a food known to choose what makes the body and mind happy, the elderly will have good knowledge or skills in consumption, it was passed down from its ancestors from a certain time and inherited with the wisdom of the villagers. Skills and skills that apply to everyday life the right consumption will make the lives of the elderly happy, as well as the elderly with the knowledge and skills of their careers. If expressed, it will make the elderly happy to express their experiences and wisdom. From the habit of being treated to succession and passed on to my child, the succession becomes a routine in the consumption of the family. If the elderly know the words modest, diligent, self-reliant, satisfied with what they have, are generous to each other, they live in a society that is happily valued and has a good quality of life.

For the elderly, the skills or ability to participate in social and cultural activities are used in everyday life to be happy, it was found that the expression of dance or music performances. As a volunteer, helping with various tasks is considered to be a contributor, and the experience teaches them to think, know, understand, evaluate, and understand their practices. This is due to the experience of the knowledge and ability to become a mind teacher, to suggest that people in that society participate in the activities. Most socialization focuses on people at the same level or under, the elderly have much knowledge, conveying the wisdom of the villagers to each other, social and cultural expressions or community traditions are based on what the elderly have their potential, health readiness, family, wealth, and time. If the elderly are ready, they will be able to participate in social activities better, observed by participating in social activities of the elderly, based on the potential and well-being of the elderly family. It found that if the elderly are ready in both physical and physical capacity, they are more likely to participate in activities than those of their age who will need to raise themselves and their families. It is difficult for the group to participate in the activity. The ability to participate in the event must be based on the potential of each elderly person, people who are ready to participate often have the opportunity to participate, but if it is an elderly person who will have to work would be difficult to find opportunities to participate in various activities. The elderly have the skills to participate in regular social activities, which will be proud to make others or society manifest and be able to effectively draw on the potential of others to develop society and the country. Also, the elderly have a feeling that they are valued. There is love and cherished for the community, which is done and takes care of the public domain of the community, as an advisor to various organizations in the community. 
International Journal of Social Science and Economic Research

ISSN: 2455-8834

Volume:06, Issue:01 "January 2021"

\section{Conclusions and Suggestion}

According to the study of the philosophy of living of the elderly in lifelong learning, it was found that the metaphysics side elderly have consumption practices, and some do not have proper practices in consumption, which uses the criteria of 6 Aor, that is (1) exercise (2) diet (3) mood (4) disease-free (5) environmental health (6) abuse. In line with Anya Plodpluang (2017), the study of the life of the elderly: a case study of the story, it found that older people over 80 years old and older were more than 80 years old, there are five key behaviors. This includes eating healthy, exercising regularly, and loving family ties, volunteering for the public, and keeping your mind calm, and using morals as a refuge. In line with ChokdeeMangkhalakri (2011), a research study on the effectiveness of elderly health management in NakhonPhanom municipality. The environmental factors associated with promoting self-health care of the elderly in NakhonPhanom municipality are very high. When considering the level of income, all sides sort the average in descending order. The following are the knowledge, cognition, self-reliance, and information acquisition, respectively, and the efficiency of the health management of the elderly in NakhonPhanom municipality is very high in all aspects. This includes eating, environmental hygiene, emotional and physical activity, respectively. About society and culture, the characteristics of volunteering to participate in activities in the form of clubs and agencies such as public service in conjunction with the elderly club, and the district health promotion hospital, etc. In the field of epistemology, the elderly know consumer consumption since childhood and knowledge gained from modern information through media such as Facebook or Line, which is very popular, and the social and cultural aspects of the Buddhist teachings combine with the wisdom of the villagers through the ordinances and learning to change each other's learning engages. In line with PongpanArunsaeng (2012), who studied the health of the elderly in the institute of health and community services, it was found that priests of each religion were psychological advocates for people who visited when they were sick, most of them are children, second to friends/neighbors, kinship spouses, and grandchildren, respectively, and in line with SaowapaPornsiripong (2012) has studied the subject of Buddhist temple with readiness to support the elderly society, it found that the temple was ready to build networks and social space for the elderly to a considerable extent, guidelines for supporting the readiness of the measure include providing a learning exchange between successful temples to work on the elderly, offering knowledge of management and elders to the monks supporting the creation of a network of temples and providing the area and environment of the temple to the elderly.

Similarly, this is consistent with PhraMahaKraisornChotipyan (Saenwong) (2014), the story of Buddhism, and the promotion of mental well-being of the elderly in the community. It was found that the results of the research suggested a model of promoting the mental state of the elderly. Include, (1) the temple and the integration of Buddhism to promote the mental well-being of the 


\section{International Journal of Social Science and Economic Research}

ISSN: $2455-8834$

Volume:06, Issue:01 "January 2021"

elderly by the development of religious places, the development of individual ordinances, the development of ordinances, the development of ordinances, (2) the management of temples to be the center of mental health care for the elderly, starting with a vision, planning, organization, navigation and command, and control, (3) participation of communities and organizations in integrating Buddhism to promote the mental well-being of the elderly by participating in the decision-making, participating, and participating in the benefits, and (4) government sectors (local government organizations, etc.) integrating Buddhism to promote the mental well-being of the elderly, by creating a public policy that is conducive to promoting health, to modify the health care system and co-ordinate and promote the environment that is conducive to community health. The logic of consumption the elderly are trained to further the potential of the relevant authorities through media and information technology, the social and cultural part is focused on participation, co-thinking, co-decision making, and co-working together to address the issues and be a mainstay in organizing activities in the community. Ethics about the consumption the elderly know to analyze what kind of food and things are consumed or suitable for use, leading to proper learning and action or decision. For the aesthetics of consumerism, the elderly rely on a way of thinking about their knowledge, self-consciousness, and experience to join the society, the social and cultural aspects are characteristic of volunteers. There is some acceptance in regards to the deteriorating body, resulting in the acceptance of changes in the body that can affect the mind. Make them optimistic and convey good things to society. In line with YupaApikomolkorn (2011), a research study on knowledge management: community health management for the elderly, found that health centers are the main mechanisms driving the management of elderly health in the community, with the municipality supporting the budget, and the elderly club initiates activities based on the interests and aptitudes of its members. In social funding, it was found that elderly club members were able to identify people's resources and resources in the community, but gave them little information about their funding and support, found that "banana leaf krathongs" and "dance" performances were performed, especially the "Lan Pho LanTham" activity because it is all self-made activities by the club. It is also consistent with Narushima M. (2008) to study the lifelong learning of the elderly 15 seniors aged 64-83 and observed 5 courses. It is about the general interest for the elderly, including handwriting, sewing, Chinese poetry, dancing, and a course on healthy exercise. In Canada, the results showed that every week, the elderly have intrinsic motivations to learn both physically and mentally. Also, the elderly are enjoying and enjoying the course. Also, most feel that they have developed themselves and are skilled at what they choose to study, and also have good relationships with teachers and classmates. And in line with Richardson, Grime, and Ong (2014), further studies from the original sample of Narushima studied the results of studies that found that most elderly people have chronic conditions. These elders alleviate the symptoms by focusing on what they are studying and practicing at home, becoming part of a daily routine to 


\section{International Journal of Social Science and Economic Research}

ISSN: $2455-8834$

Volume:06, Issue:01 "January 2021"

heal physical health suffered from chronic diseases, and mental health, not to be obsessed or negatively charged with their illness. This may be because the learning conditions of the elderly begin first and the participation of individuals and outside communities. It's all about consumerism and social, cultural, and environmental issues, and it's all about learning for the elderly.

However, policy-level suggestions the researchers analyzed the findings that suggest that (1) should be researched on the empowerment and development of the life potential of the elderly to be holistically happy, namely the body, to improve the quality of life of the elderly to cover all regions of the country, and (2) there should be a research study on the integration of knowledge to improve the quality of life of the elderly in multicultural societies, namely, diversity of race, religion, language, ethnicity, lifestyle, and traditions. As well as the recommendation, the operator level is (1) there should be a comprehensive research study on the approach of aged care. To provide services to the elderly, it covers many dimensions and all areas in Thai society, including physical health, mental health, Thai traditional medicine, and modern medicine are suitable and in line with the way of life in today's society, and (2) there should be a research study on the participation in aged care by individuals and organizations for sustainable development of the quality of life of the elderly, namely individuals close to the elderly, local government, non-governmental organizations, to warm and sustain elderly people living long lives and well-being at the end of their lives.

\section{References}

Academic Office, Secretariat Office House of Representatives. 2018. Access to the aging society of Thailand. Bangkok: Academic Office, Secretariat of the House of Representatives.

Arunsang, P. 2012. Health assessment of adults and elderly for nurses. KhonKaen: Faculty of Nursing KhonKaen University.

Apikomolkorn, Y. 2011. Knowledge management: Community health management for the elderly. Lampang: Faculty of Science LampangRajabhat University.

Boonsritan, P. 2020. Buddhist Ethics. Research and production / revision of teaching documents, textbooks, teaching materials for the year 2017, Chiang Mai University: Department of Philosophy and Religion, Faculty of Humanities.

Burawat, S. 2001. Philosophy.4th edition. Bangkok: Siam.

Carter, V. Good. 1959. Dictionary of Education. N.Y. :McGraw Hill Book Co.Inc., pp.395. 
International Journal of Social Science and Economic Research

ISSN: 2455-8834

Volume:06, Issue:01 "January 2021"

Dokbua, F. 1996. Comparative Religion. Bangkok: Buraphasarn Printing House.

Dokbua, F. 2002. Indian Philosophy Point. Bangkok: Siam Publishing House.

Life-long Learning, Policy Brief, Organization for Economic Co-operation and Development, OECD. 2004. LIFELONG LEARNING FOR ALL POLICY DIRECTIONS. A New Framework for Assessment, PISA, Paris.

Mangkhalakri, C. 2011. Efficacy of Elderly Health Management in

NakhonPhanomMunicipality.Bangkok: Thaksin University.

Methavittayakul, S. 1997. Introduction to Philosophy. 2nd edition, Bangkok: O.S. Printing House.

Ministry of Social Development and Human Security. 2014. Policy of the Ministry of Social Development and Human security. Bangkok: Ministry of Development.

Narushima, M. 2008. More than nickels and dimes: the health benefits of a community-based lifelong learning program for older adults.International Journal of Lifelong Education, 27, 6, (pp.673-92).

Office of Child Welfare Promotion and Protection. 2014. Promotion of welfare and protection of children, youth, the disadvantaged, the disabled and the elderly. Bangkok: Office of the Promotion and Protection of the Elderly Bureau of Promotion Welfare and protection of children, youth, the disadvantaged, the disabled and the elderly Ministry of Social Development And human security.

Office of Health Promotion. 2019. Statistics of the elderly in Thailand. Nonthaburi: Department of Health, Ministry of Public Health.

PhraDharmakosajarn (PrayoonDhammajitto). 2012. Greek Philosophy: The Origin of Western Wisdom. Edition 6. Bangkok: Siam Publishing House.

PhraMahaKraisornChotipanyo (Saenwong). 2014. Buddhism and the promotion of mental wellbeing of the elderly in the community. Research report, Buddhist Research Institute.Mahachulalongkornrajavidyalaya University.

Pholsompob, T. 2004. Initial advice. 3rd edition, Bangkok: University Press. Ramkhamhaeng. Plodpluang, A. 2017. The study of the lifestyle of the elderly: a case study in a narrative form. 


\section{International Journal of Social Science and Economic Research}

ISSN: 2455-8834

Volume:06, Issue:01 "January 2021"

Research Articles Journal of NarathiwatRajanagarindra University Humanities and Social Sciences Year $4 \quad$ Issue 1 (January - June).

Pornsiriphong, S. 2012. Buddhist temple and readiness to support the elderly society. Bangkok: MahidolUniversity.

Sangsri, S. 2006. Distance education.1st edition, Printing press, SukhothaiThammathirat Open University.

Sunanchai, S. 2005. Learning and education (video ed.).Nonthaburi: Office of Educational Technology, SukhothaiThammathirat Open University.

Synthesis-Asia Pacific Competency Framework. 2016. Sustainable Development

Process.UNESCO Office Bangkok and Regional Bureau for Education in Asia and the Pacific.

Ratanasuwan, P. 1989. Lectures on Buddhist Philosophy. 5th edition, Bangkok: Spiritual Research Office.

Richardson, J.C., Grime, J.C., Ong. 2014. keeping going': chronic joint pain in older people who describe their health as good. BN Ageing Soc. Sep; 34(8): (pp.1380-1396).

Royal Academy. 2011. Dictionary of the Royal Institute of Thailand.Bangkok: Company. SiriWattanaInterprint Public Company Limited.

Wicksungnoen, J. 2010. Satisfaction toward the social welfare provision for the elderly of the sub-district administrative organization in Non Thai district. NakhonRatchasima Province.Master of Arts Thesis Project management and project assessment.ThonburiRajabhat University.

Wongsawan, S. 2000. Introduction to Philosophy. 2nd edition, Bangkok: Phitthaya Alphabet. 